\title{
AMÉRICA LATINA: 200 ANOS DE FATALIDADE*
}

\author{
AMÉRICA LATINA: 200 AÑOS DE FATALIDAD
}

\section{LATIN AMERICA: 200 YEARS OF FATALITY}

DOI: http://doi.org/10.9771/gmed.v13i3.47341

Bolívar Echeverría ${ }^{1}$

[Tradução: Thays Fidelis²]

Suave Pátria, vendedora de chia: quero sequestrar-te na quaresma opaca, sobre um cavalo, e com chocalho, e entre os tiros da polícia.

R. López Velarde, La suave pátria

Não falta ironia no fato de que as repúblicas nacionais que surgiram no século XIX na América Latina acabaram se comportando contra si mesmas apesar de terem declarado detestar um modelo, o da sua própria modernidade - a modernidade barroca, configurada no continente americano durante os séculos XVII e XVIII. Pretendendo se "modernizar", ou seja, obedecendo a um claro desejo de abandonar o próprio modelo e adotar um mais exitoso em termos mercantis - se não o anglo-saxão ao menos o da modernidade proveniente da França e imposto na península ibérica pelo Despotismo Ilustrado -, as camadas poderosas das sociedades latino-americanas se viram compelidas a construir repúblicas ou Estados nacionais que não eram, que não podiam ser, como elas mesmas queriam, cópias ou imitações dos Estados capitalistas europeus; que deveriam ser outra coisa: representações, versões teatrais, repetições miméticas deles mesmos; edifícios nos quais, de maneira inconfundivelmente barroca, o imaginário tende a se pôr no lugar do real.

E é que suas tentativas de seguir, copiar ou imitar o produtivismo capitalista iam de encontro vez ou outra com o gesto de rejeição da "mão invisível do mercado", que parecia ter a responsabilidade de encontrar para essas empresas estatais da América Latina uma localização especial dentro da reprodução capitalista global, uma função âncora. Na conformação conflitiva da taxa de lucro capitalista, elas rebaixaram sistematicamente a participação que corresponde forçosamente à renda da terra, recuperando para o capital produtivo, mediante um bypass, uma parte da mais-valia gerada nesse capital e aparentemente "desviado" para pagar pelo uso da natureza que os senhores (sejam eles privados, como os fazendeiros, ou públicos, como a república) ocupam com violência. Graças a essas empresas estatais, a ação das suas "forças vivas", 
as fontes de matéria-prima e de energia - cuja presença no mercado, junto a da força de trabalho barata de que dispõe, constitui o fundamento da sua riqueza - tiveram seus preços especialmente reduzidos no mercado mundial. Em Estados como os latino-americanos, os donos de terras, públicos ou privados, foram levados "pelas circunstâncias" a reduzir sua renda, e com isso indiretamente a renda da terra em toda a “economia-mundo" ocidental, em benefício do lucro do capital produtivo concentrado nos Estados da Europa e América do Norte. Ao fazê-lo, condenaram a massa de dinheiro-renda de suas próprias repúblicas a permanecer sempre na forma de capital-mercadoria, sem alcançar a medida crítica de dinheiro-capital que vinha sendo necessária para dar o salto até a categoria de capital produtivo, deixando-os - pese os contados exemplos de "grandes homens da indústria e o progresso" - na qualidade de simples rentistas disfarçados de comerciantes e banqueiros, e condenando suas repúblicas à existência subordinada que sempre tiveram. Porém, diminuída, reduzida a uma discreta "mordida" nessa renda desvalorizada da terra, a massa de dinheiro que o mercado colocava a disposição das empresas latino-americanas e a seus Estados foi suficiente para financiar a vitalidade dessas forças vivas e o desperdício "discretamente pecaminoso" dos happy few que se reuniam em torno delas. A sobrevivência dos outros, os quase "naturais", os sócios não plenos do Estado ou os semi-cidadãos da república, seguiram a cargo da natureza selvagem e da magnanimidade "dos de cima", ou seja, da gananciosa vontade divina. Mas, sobretudo, os lucros dessas empresas e seus Estados foram suficientes para outorgar verossimilhança à imitação ou representação mimética que permitia a esses últimos voltarem a ser o que não eram, a fazer "como se" fossem Estados instaurados pelo capital produtivo, e não simples assembleias de proprietários de terras e comerciantes a seu serviço.

Privadas dessa fase ou momento chave no qual a reprodução capitalista da riqueza nacional passa pela reprodução da estrutura técnica dos seus meios de produção - por sua ampliação, fortalecimento e renovação -, as repúblicas que se assentaram sobre as populações e os territórios da América Latina têm mantido uma relação com o capital - com o "sujeito real” da história moderna, emergido da alienação da subjetividade humana - que é sempre muito mediada ou indireta. Desde as "revoluções de independência" têm sido repúblicas dependentes de outros Estados maiores, mais próximas a esse sujeito determinante; situação que tem implicado numa diminuição substancial do seu poder real e, consequentemente, da sua soberania. A vida política que foi encenada neles tem sido, dessa maneira, mais simbólica que efetiva; quase nada do que se disputa no seu cenário tem consequências verdadeiramente decisivas ou que consigam ir além da aparência. Dada sua condição de dependência econômica, às repúblicas nacionais latino-americanas só é permitido trazer ao foro da sua política as disposições emanadas do capital uma vez que estas tenham sido já filtradas e interpretadas convenientemente nos Estados onde ele tem sua residência preferida. Têm sido Estados capitalistas adotados só de longe pelo capital, entidades fictícias, separadas da "realidade"3.

De todo modo, a pergunta é: os resultados da fundação dos Estados nacionais, há dois séculos, nos quais vivem atualmente os latino-americanos e que os definem pelo que são, não justificam de maneira suficiente os festejos desse ano? Os argentinos, brasileiros, mexicanos, equatorianos etc., não devem estar orgulhosos de ser o que são, ou de ser simplesmente "latinos"?

Não há dúvida de que, inclusive em meio à perda de autoestima mais dura é impossível viver sem um certo grau de autoafirmação, de satisfação consigo mesmo e, portanto, de "orgulho" de ser o que se é, 
mesmo que essa satisfação e esse "orgulho" devam se esconder tanto que se tornem imperceptíveis. E dizer autoafirmação é o mesmo que dizer reafirmação de identidade. Disso se torna pertinente perguntar se essa identidade que os latino-americanos conseguiram se orgulhar e que talvez queiram festejar feliz e ingenuamente nesse ano não segue sendo talvez precisamente a mesma identidade enganadora, aparentemente harmonizadora de contradições intransponíveis entre os opressores e os oprimidos, idealizada ad hoc pelos impulsionadores das repúblicas "pós-coloniais" depois do colapso do Império Espanhol e das "revoluções" ou "guerras de independência" que os acompanharam. Uma identidade que, por isso, a julgar pela retórica ostentosamente bolivariana da mídia de massa que nesses dias convocam a exaltá-la, parece se fundir em outra, de essência igual a anterior, mas de alcance continental: a de uma vasta nação, a "nação latina", que um espantoso mega Estado capitalista latino-americano, ainda em formação, estaria prestes a se levantar. E é que, analisado com mais calma, o orgulho por esta identidade teria de ser um orgulho bastante quebrado; assim, se trata de uma identidade afetada por doenças que a convertem também, e convincentemente, em um motivo de vergonha, que desperta o desejo de se separar dela.

A "Revolução" de Independência, acontecimento fundante das repúblicas latino-americanas que se auto festejam esse ano, veio reeditar, "corrigido e aumentado" o abandono que o Despotismo Ilustrado trouxe consigo de uma prática de convivência que inclusive havia prevalecido nas sociedades americanas durante todo o longo "século barroco", a prática de miscigenação; uma prática que - apesar de sofrer o acentuado efeito hierárquico das instituições monárquicas as que se submetia - teria um modo bastante aberto de integração de todo o corpo social dos habitantes do continente americano. Bem-vindo pela metade dos criollos hispânicos e rejeitado pela outra, a dos criollos indígenas, o Despotismo Ilustrado chegou, importado da França dos Bourbons4. Com ele foi implantado na América a distinção entre a "metrópole" e a "colônia" e se consagrou ao modo de vida da primeira, com suas filiais ultramarinas, como o único "portador de civilização"; um modo de vida que, por consequência, devia primeiro se distinguir e se separar dos modos de vida da população natural colonizada, para seguir com sua subjugação e aniquilação. Este abandono da miscigenação na prática social, a introdução de um "apartheid latino" que, além de hierarquizar o corpo social, o divide em uma parte convocada e outra rejeitada, estão na base da criação e da permanência das repúblicas latino-americanas. Se trata de repúblicas cujo carácter excludente ou "oligárquico" - no sentido etimológico de "relativo a poucos" -, próprio de todo Estado capitalista, se encontra exagerado até o absurdo, até a automutilação. Os "muitos" que ficaram de fora dela são nada menos que a grande população indígena que sobreviveu ao "cosmocídio" da Conquista, os negros escravizados e trazidos da África e os mestiços e mulatos “de baixa ralé”. Quase um século depois, os mesmos criollos franco-iberizados - "neoclássicos" - que desde a primeira metade do século XVIII se impuseram com seu "despotismo ilustrado" sobre os outros, os indígenas - "barrocos" - passaram a conformar, já sem o cordão umbilical que os atava à "pátria mãe” e sem o estorvo dos espanhóis peninsulares, a classe dominante dessas repúblicas que se regozijam hoje orgulhosamente pela sua eterna juventude.

O projeto implícito na constituição dessas repúblicas nacionais, que desde o século XIX começaram a flutuar como ilhas prepotentes sobre o corpo social da população americana, impregnando neles suas intenções e sua identidade, tinha entre seus conteúdos uma tarefa essencial: retomar e acabar o processo de 
conquista do século XVI, que se desvirtuou durante o longo século barroco. É essa identidade definida em torno à exclusão, herdada dos criollos ilustrados orgulhosos, a mesma que, ligeiramente transformada por duzentos anos de história, e a conversão da modernidade europeia em modernidade "americana" que se festeja em 2010 com bumbos e pratos mas - curiosamente - "sob estritas medidas de segurança". Se trata de uma identidade que somente com a ajuda de uma forte dose de cinismo poderia ser plenamente um motivo de "orgulho"...a não ser que, em virtude de um wishful thinking poderoso - acompanhado de uma desesperada vontade de ofuscação da realidade -, como o que se destaca na região sul-americana atualmente, percebida como algo a ser substituído por outro futuramente, totalmente transformado no sentido democrático.

É surpreende a insistência com que os movimentos e os líderes que pretendem construir atualmente a nova república latino-americana se empenham em confundir - como López Velarde parecia fazer na Suave Pátria - ${ }^{5}$, sob o nome de Pátria, um continuum que existiria entre aquela nação-estado construída há duzentos anos como deformação da "nação natural" latino-americana, com sua identidade marmorizada e "neoclássica", e esta mesma "nação natural", com sua identidade dinâmica, variada e esfumaçada; um continuum que, sarcasticamente, não tem consistido de fato em outra coisa a não ser na repressão desta pela primeira. É como se quisessem desconhecer ou ignorar, por ser desmobilizante, reconhecer aquela "guerra civil" surda e desarticulada, mas efetiva e sem repouso que tem tido e tem lugar entre a nação-estado das repúblicas capitalistas e a comunidade latino-americana enquanto tal, marginalizada e oprimida por elas e sendo, portanto, contrárias e combativas. Trata-se de uma confusão que leva a ocultar o sentido revolucionário desse wishful thinking dos movimentos sociais, desdenhando a superação do capitalismo como o elemento central das novas repúblicas e a contentar-se em acabar com o caráter destrutivo que se concentraria no "neo" do "neoliberalismo" econômico, restaurando o liberalismo econômico "sem adjetivos" e o remodelando como um "capitalismo com rosto humano". É um quid pro quo que, sob o pressuposto de uma identidade comum trans-histórica, compartilhada pelos opressores e oprimidos, exploradores e explorados, integrados e expulsos, pede que o julgue como um engano historicamente "produtivo", útil para reproduzir a unidade e a permanência indispensáveis em toda a comunidade dotada de uma vontade de transcendência. Um quid pro quo cuja eliminação seria um ato de "lesa-pátria".

De certa forma, as "Festas do bicentenário", mais que uma comemoração, parecem festas de autoproteção contra o arrependimento. Ao serem fundadas, as novas repúblicas estiveram diante de uma grande oportunidade, a de romper com o passado despótico ilustrado e recompor o corpo social que este tinha separado. No lugar dele, no entanto, preferiram exacerbar essa separação - "último dia de despotismo e primeiro do mesmo", leia-se na pintura de um muro em Quito daquela época - sacrificando a possível integração na qualidade de cidadãos desses membros da comunidade que o produtivismo ilustrado tinha descartado por serem "disfuncionais". E decidiram, ademais, acompanhar a exclusão com uma parcialização da totalidade orgânica da população do continente americano, que era uma realidade inquestionável pese às tão invocadas dificuldades geográficas.

Enfrentados os resultados catastróficos da sua história bicentenária, o que menos se poderia esperar delas é um ânimo de contrição e arrependimento. Mas não acontece assim: na prática o que acontece é a 
"negação", a "transmutação do pecado em virtude". Esta cegueira autopromovida diante do sofrimento que não era necessário viver, mas que se viveu por culpa delas durante tanto tempo, as distancia de todo comportamento autocrítico e as leva, ao contrário, a levantar arcos triunfais e a abrir concursos de apologia histórica entre os letrados e os artistas.

Os festejos de 2010 são em média os da autocomplacência que aparentam não poder ocultar uma certa característica patética; são cerimônias que traem a si mesmo e mostram no fundo algum feitiço contra uma morte anunciada. Em meio às incertezas acerca do seu futuro, as repúblicas oligárquicas latinoamericanas buscam agora a maneira de se restaurar e se recompor mesmo que seja fazendo cinicamente mais do mesmo, desperdiçando a migalha de soberania que ainda tem em suas mãos. Festejam sua existência bicentenária e ao mesmo tempo, sem se confessar, usam esses festejos como amuletos que lhes sirvam para afugentar a ameaça de desaparição que pendem sobre elas.

O aparato institucional republicano foi desenhado no século XIX para organizar a vida dos relativamente poucos proprietários de patrimônio, os únicos cidadãos verdadeiros ou realmente admitidos nas repúblicas. Com a marcha da história ele teve de ser utilizado politicamente para resolver uma dupla tarefa adicional: devia primeiro atender assuntos que correspondessem a uma "base social" que as repúblicas necessitavam ampliar e que o conseguiriam abrindo-se de maneira dosada à população estruturalmente marginalizada, mas sem afetar e menos ainda abandonar seu inerente caráter oligárquico. Era um aparato condenado a viver em crise permanente. "Anti-gattopardiano", suicida, a teimosia dessas repúblicas em praticar um "colonialismo interno" - ignorando a tendência histórica geral que exigia ampliar o sustento demográfico da democracia - as levou a deixar que sua vida política se consumisse até o limite da ilegitimidade, provocando assim o colapso desse aparato. Ampliado e remendado sem rima ou razão, burocratizado e distorcido ao ter que cumprir uma tarefa tão contraditória, o aparato institucional viu sua disfuncionalidade ser agudizada até o extremo que a própria ruling class começou a se desentender dele. Abdicando da comissão bem paga que o capital tinha feito e que a converteu em uma elite consanguínea estruturalmente corrupta; tirando da mesa o tabuleiro do jogo político democrático representativo e devolvendo-o ao capital "no total" o mando direto sobre os assuntos públicos, esta ruling class diminuiu a si mesma até não ser mais que um conglomerado inorgânico de poderes factuais, dependentes de outras transnacionais, com suas máfias de todo tipo - o mesmo legal que criminosos - e seus manipuladores midiáticos.

Praticamente desmantelada e abandonada por seus "verdadeiros" donos, a "superestrutura política" que estas repúblicas se deram originalmente e sem a qual diziam não poder existir, se encontra nos nossos dias em meio a um estranho fenômeno; está passando para as mãos dos movimentos sociopolíticos antioligárquicos e populistas que antes a repudiavam tanto ou mais do que ela os rechaçava. São esses movimentos os que agora, depois de uma "Vitória de Pirro"6, buscam forçar uma saída da sua perplexidade e se apressam para criar uma alternativa entre restaurar e revitalizar essa estrutura institucional ou abandonála e substituí-la por outra. Trata-se de conglomerados sociais dinâmicos que têm emergido dentro daquela massa "politizada" de marginais e empobrecidos, gerada como subproduto da chamada "democratização" 
das repúblicas oligárquicas latino-americanas; uma massa que, sem deixar de estar excluída da vida republicana, tinha sido semi-integrada nela como "exército eleitoral de reserva".

As "festas do bicentenário", convocadas numa única voz por todos os governos das repúblicas latino-americanas e organizadas separadamente em cada uma delas, pareciam ser eventos completamente distante "aos de baixo", espetáculos republicanos "de linhagem", transmitidos com toda sua suntuosidade pelos monopólios televisivos, ao que essas maiorias assistiriam somente como simples espectadores boquiabertos, entusiasmados ou chateados. No entanto, são festas que essas maiorias têm transformado em suas, e não somente para ratificar sua "tendência festiva" mundialmente conhecida, mas também para tornar evidente, armados muitas vezes apenas de ironia, a realidade da exclusão contornada pela ficção da república bicentenária.

As nações oligárquicas e as respectivas identidades artificialmente únicas e unificadoras, às que as distintas porções dessa população pertencem tangencialmente, não têm sido capazes de se constituir como entidades inquestionavelmente convincentes e aglutinadoras. Sua debilidade é da empresa histórica estatal que as sustenta; uma debilidade que agrava sua origem. Duzentos anos vivendo em referência a um estado ou república nacional que as marginaliza sistematicamente, mas sem retirá-las do seu âmbito de gravitação, tem levado a maioria da América Latina a se apropriar dessa nacionalidade imposta, e a fazê-lo de uma maneira singular.

A identidade nacional das repúblicas oligárquicas se confecciona a partir das características aparentemente "únicas" do patrimônio humano do estado, assentado em seus usos e costumes peculiares sobre o patrimônio territorial do mesmo. É o resultado de uma funcionalização das identidades vigentes nesse patrimônio humano, que adapta e populariza convenientemente esses ditos usos e costumes de maneira que se adequem aos requerimentos da empresa estatal na sua luta econômica com os outros estados no cenário do mercado mundial.

A inegável gratuidade ou falta de necessidade do artifício nacional é um fato que na América Latina é colocado em evidência com muito mais frequência e sem pudor que em outras situações históricogeográficas da modernidade capitalista. Mas é uma gratuidade que, além de enfraquecer o estado, tem também efeitos de outra ordem. Ela é o instrumento de uma proposta civilizatória moderna, mesmo que reprimida na modernidade estabelecida, sobre a autoafirmação identitária dos seres humanos. A "nação natural" mexicana ou brasileira não só não pode ser substituída pela nação-estado desses países senão que, ao contrário, é ela quem a superou e a integrou lentamente. Em virtude da precariedade da sua imposição, a nação-estado tem servido às nações latino-americanas como mostra da gratuidade ou falta de fundamento de toda identidade de autoafirmação, o que é o instrumento idôneo para vencer a tendência ao substancialismo regionalista que é próprio de toda nação moderna bem sustentada. São pouquíssimas, por exemplo, as características comuns presentes na população da república do Equador - república desenhada sobre os joelhos do Libertador -, advindas da história ou inventadas atualmente, que puderam dar uma razão de ser sólida e inquebrantável à nação-Estado equatoriana. No entanto, é inegável a vigência de uma "equatorianidade" - elevada no ar, se quiserem, artificial, esfumaçado e de múltiplas faces —, que os 
equatorianos reconhecem e reivindicam como um traço identitário importante do que fazem e do que são, e que lhes abre ao mesmo tempo, sobretudo na dura escola da migração, à miscigenação cosmopolita.

A disposição à autotransformação, a aceitação dialógica - não simplesmente tolerante - de outras identidades, vêm precisamente do pressuposto de um contingente que tem em toda identidade, da sua fundamentação na pura vontade política, e não em algum encargo mítico ancestral, que por mais terreno que pareça termina por tornar-se sobrenatural e metafísico. Esta disposição é a que dá à afirmação identitária das maiorias latino-americanas - concentradas em algo muito sutil, praticamente uma fidelidade arbitrária ao invés de uma "preferência de formas" -, o dinamismo e a capacidade de metamorfose que seria requerido por uma modernidade imaginada para além da sua estagnação capitalista.

\begin{abstract}
Notas
* [N. da T.: o presente ensaio é, provavelmente, o último que o autor escreveu antes da sua desafortunada morte em 5 de junho de 2010, e foi publicado originalmente na revista eletrônica Simpermiso em 11 de abril de 2010 <http://www.bolivare.unam.mx/ensayos/america_latina_200_anos_de_fatalidad> e na revista Contrabistorias, n. 15, setembro 2010/fevereiro 2011, p. 79-85 < https://issuu.com/revistacontrahistorias/docs/contrahistoriasvirtual15>. Publicado na web Bolivar Echeverría: discurso crítico y filosofía de la cultura (www.bolivare.unam.mx) sob uma licença Creative Commons 2.5.]

${ }^{1}$ Bolívar Echeverría (1941 - 2010), nascido em Riobamba/Equador, foi um importante filósofo latino-americano reconhecido por suas importantes discussões sobre modernidade capitalista e o pensamento de Karl Marx. Desde jovem se destacou no movimento estudantil do seu país e no estudo de filósofos vinculados ao existencialismo. Em 1962, realizou uma viagem à Alemanha, onde conheceu a obra de importantes autores marxistas como György Lukács, Rosa Luxemburgo, Frantz Fanon e os debates da chamada Escola de Frankfurt, que influenciarão fortemente o seu pensamento. Em 1974, ingressou na Universidad Autónoma de México (Unam) para graduar-se em filosofia e fazer seus estudos de pós-graduação em filosofia e economia, tornando-se professor e pesquisador da referida universidade até o seu falecimento. O seu fazer profissional, altamente produtivo, concretizou-se nas suas grandes contribuições aos debates de cultura e capitalismo, modernidade na América Latina, as interpretações da obra de Marx, o valor de uso e a reprodução capitalista. Entre as suas principais obras, podemos destacar: A modernidade do barroco (1998), O discurso crítico de Marx (1986), Valor de uso e utopia (1998), Modernidade e "branquitude" (2010). [N. da E.: agradecemos a Lourdes Flores Bordais pela redação desta minibiografia do autor.]

2 Doutoranda em Serviço Social pela Universidade Federal de Alagoas (Ufal) e assistente social do Hospital Regional do Norte (Alagoas). Mestre em Serviço Social pela Universidade Federal do Rio de Janeiro (UFRJ). Pesquisadora do grupo de Pesquisa Estado, Direito e Capitalismo Dependente (http://dgp.cnpq.br/dgp/espelhogrupo/202118) e do Grupo de Pesquisa Sobre Reprodução Social (http://dgp.cnpq.br/dgp/espelhogrupo/172616). Currículo Lattes: http://lattes.cnpq.br/7930145942348252.

Orcid: https://orcid.org/0000-0002-8713-0451. Email: thays.karoll@gmail.com. Coautora do artigo Fascismo e profissionalização da contrarrevolução no Brasil e coorganizadora do livro Economia, política e dependência: contribuições para análise do Estado e da superexploração da força de trabalho no capitalismo dependente (Edufal, 2020).

${ }^{3} \mathrm{O}$ ilusório da política real na vida dessas repúblicas se ilustra perfeitamente na facilidade com que certos artistas ou certos políticos têm transitado de ida e volta da arte à política; houve romancistas que foram bons governantes (Rómulo Gallegos), e revolucionários que foram magníficos poetas (Pablo Neruda); assim como outros que foram bons políticos quando pintores e bons pintores quando políticos. Nada tem sido realmente real, senão tudo realmente maravilhoso.

${ }^{4}$ [N. da E.: referente à Casa Real dos Bourbons, que reinou na Espanha e na França.]

5 A "pátria suave" de López Velarde - aquela que quem hoje a devasta se dá ao luxo hipócrita de tratar nostalgicamente -, apesar do caráter pró-oligárquico que pode ter sua aparência idílica provinciana (com tudo, inclusive patrões "generosos" como o de Rancho Grande), resulta ser, no final das contas, todo seu contrário. É corrosivo da exclusão aceita e consagrada. O erotismo promíscuo da "nação natural" que se soma nela, sub-reptício, mas abrangente, não reconhece nem as castas nem as classes que são indispensáveis às repúblicas da "gente civilizada", zomba da sua razão de ser.

${ }^{6}$ [N. da T.: no original, "ganado el tigre en la feria", uma expressão que diz sobre ganhar um prêmio com ônus muito grande.]
\end{abstract}

